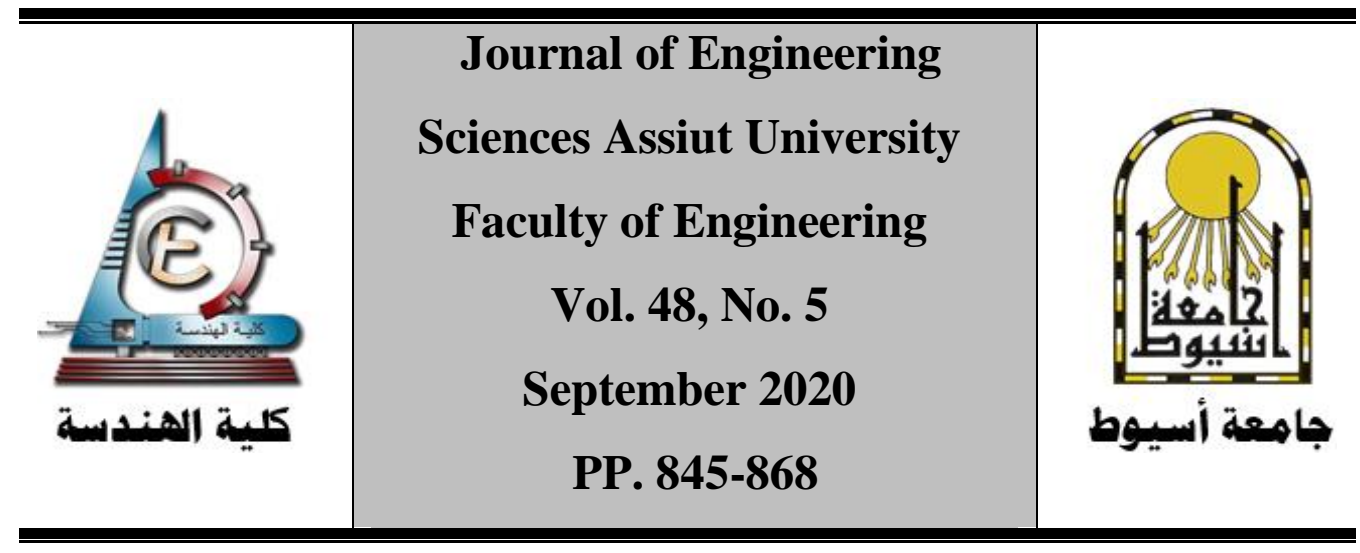

\title{
AUTOMATIC INDICES BASED CLASSIFICATION METHOD FOR MAP UPDATING USING VHR SATELLITE IMAGES
}

\author{
Mohamed Fawzy*,1, Yasser G. Mostafa ${ }^{2}$, Farag Khodary ${ }^{1}$
}

${ }^{1}$ Civil Eng. Dept., Faculty of Engineering, South Valley University, Qena, Egypt

${ }^{2}$ Civil Eng. Dept., Faculty of Engineering, Sohag University, Sohag, Egypt

Corresponding author: Mohamedfawzy@eng.svu.edu.eg

Received 5 April 2020; Revised 5 May 2020; Accepted 11 May 2020

\begin{abstract}
Urban land cover classification using Very High Resolution (VHR) satellite images is a very important source of information for map updating. Egyptian environment has more challenges in feature extraction. The main problem lies in the spectral similarity between different land cover classes. Also, great diversity in sizes, shapes, and materials of each class. The main aim of this work is to represent a new automatic indices-based classification method for map updating using VHR satellite images. The method uses a set of spectral indices with their thresholds in consecutive order, chosen based on WorldView-2 (WV-2) bands, to classify land cover in the Egyptian environment. For this study, WV-2 satellite images with eight spectral bands were used. The proposed method is compared with five traditional classification methods; Minimum distance, Spectral angle mapper, Mahalanobis distance, Spectral correlation mapper, and Maximum likelihood method, which included in ERDAS 2015 software, for validation purpose and checking its stability. The results show that the extracted features with the proposed method can contribute significantly to update Egyptian medium scale maps. The average overall accuracy achieved with the proposed approach $(75.31 \%)$ is higher than those obtained using Minimum distance (54.0\%), Spectral angle mapper (69.50\%), and Mahalanobis distance $(73.63 \%)$. Also, it is near to those obtained by the Spectral correlation mapper (76.50\%), and Maximum likelihood method (78.25\%).
\end{abstract}

Keywords: Feature extraction, satellite image, spectral indices, map updating, worldview 2 


\section{Introduction}

Mapping urban features using high-resolution satellite images is an effective technique for supporting planning, resource management, reporting, and infrastructure development. Land cover classification techniques divide image pixels into classes based on spectral reflectance value. Although manual classification techniques were introduced to improve within-class impervious surface classifications, these techniques involve complex processing and high calculation times [1]. Automatic and efficient classification methods are needed to maximize the benefit of such data. The automatic land cover classification has been a challenging task since the launch of the first VHR satellite in 1999 [2].

Earth's surface features give different reflectance in the spectrum range. Satellites such as Worldview is characterized by the presence of a sensor capable of distinguishing the spectrum reflectance with a high capability. WorldView-2 sensor provides a high-resolution panchromatic band with $0.50 \mathrm{~m}$ resolution and eight multispectral bands with $2 \mathrm{~m}$ resolution [3]. Image indices provide the advantage of highlight features of interest on the image and enhancing spectral values that present land cover type. Band ratio is a simple index that emphasizes object anomalies, which enhance class separations. A set of normalized difference indices was developed using WV-2 bands. For example, Normalized Difference Water Index (NDWI), Normalized Difference Vegetation Index (NDVI), Normalized Difference Bare Soil Index (NDBSI), Forest and Crop Index (FCI) [4].

In spectral indices technique, data extracted from satellite images by establishing a threshold value in an index image. Thresholding is simply the method of dividing an image by setting all pixels whose values are greater than the threshold level to high and the remaining pixels to low. The accuracy of features extracted from each index depends on the accuracy of the determined threshold value. The threshold value can be selected by different ways, such as Gaussian mixture model [5], bimodal histogram splitting [6], the number of peaks and valleys [7], and objectively by visual inspection [8]. The thresholding technique has many advantages, including speed and simplicity, as well as the availability in most image processing software. The main disadvantage of thresholding is the difficulty in choosing a suitable threshold value.

The main objective of this research is to represent an automatic indicesbased method for feature extraction using VHR satellite images for map updating in the Egyptian environment. The remainder of this paper is organized as follows. Section 2 presents the methodology. Section 3 describes the data pre-processing. Feature extraction indices are described in section 4 . Section 5 illustrates the proposed indices-based method. Standard 
image classification methods are shown in sec 6. Section 7 shows information content, and section 8 shows map updating. Results and discussions are explained in section 9. Finally, conclusions are illustrated in section 10 .

\section{Methodology}

To achieve the research objective, the following methodology (Fig. 1) is applied then the results are evaluated.

- The high spatial resolution pan image and the multispectral resolution image are integrated to obtain a high spatial and spectral quality satellite image.

- Geometric correction process is carried out to rectify WorldView-2 satellite image to Egyptian Transverse Mercator.

- Shadow restoration process is applied through two steps: detection and compensation.

- Four study areas with different degree of planning contain five land cover classes water, vegetation, bare soil, building, and road are chosen.

- Feature extraction indices are compared to select the best index for each class.

- The best feature extraction indices are applied in consecutive order to automatically classify satellite images.

- Accuracy assessment is performed for the classified images using the error matrix.

- The information content of WorldView-2 image is evaluated for updating 1:5000 Egyptian maps.

\section{Data pre processing}

Data pre-processing is the tasks required to represent the satellite images in a more appropriate form. This can lead to better interpretation and extract the maximum information. In this research, image pre-processing contains data fusion, geo-referencing, and shadow correction. 


\subsection{Study area and data used}

Qena governorate is one of the historical governorates in upper Egypt. It lies between latitude $25^{\circ} 42^{\prime} 24.45^{\prime \prime} \& 26^{\circ} 43^{\prime} 40.4^{\prime \prime} \mathrm{N}$ and longitude $31^{\circ} 52^{\prime} 4.56^{\prime \prime} \&$ $33^{\circ} 36^{\prime} 0.64 " \mathrm{E}$, with total area about $11389 \mathrm{~km}^{2}$ [9]. It has various urban areas with different degrees of planning. In this research, an image from WorldView-2 satellite captured in March 2017 is used (Fig. 2-a), Table 1 shows WorldView-2 specifications. Also, a map at scale 1:5000 produced by Central Agency for Public Mobilisation and Statistics compiled from aerial photographs at 2006 is used (Fig. 2-b). Based on prior knowledge of the study area and visual analysis of the WorldView-2 image, four study areas with different degrees of planning and land cover types (water, vegetation, bare soil, building, and road) were chosen (Fig. 3).

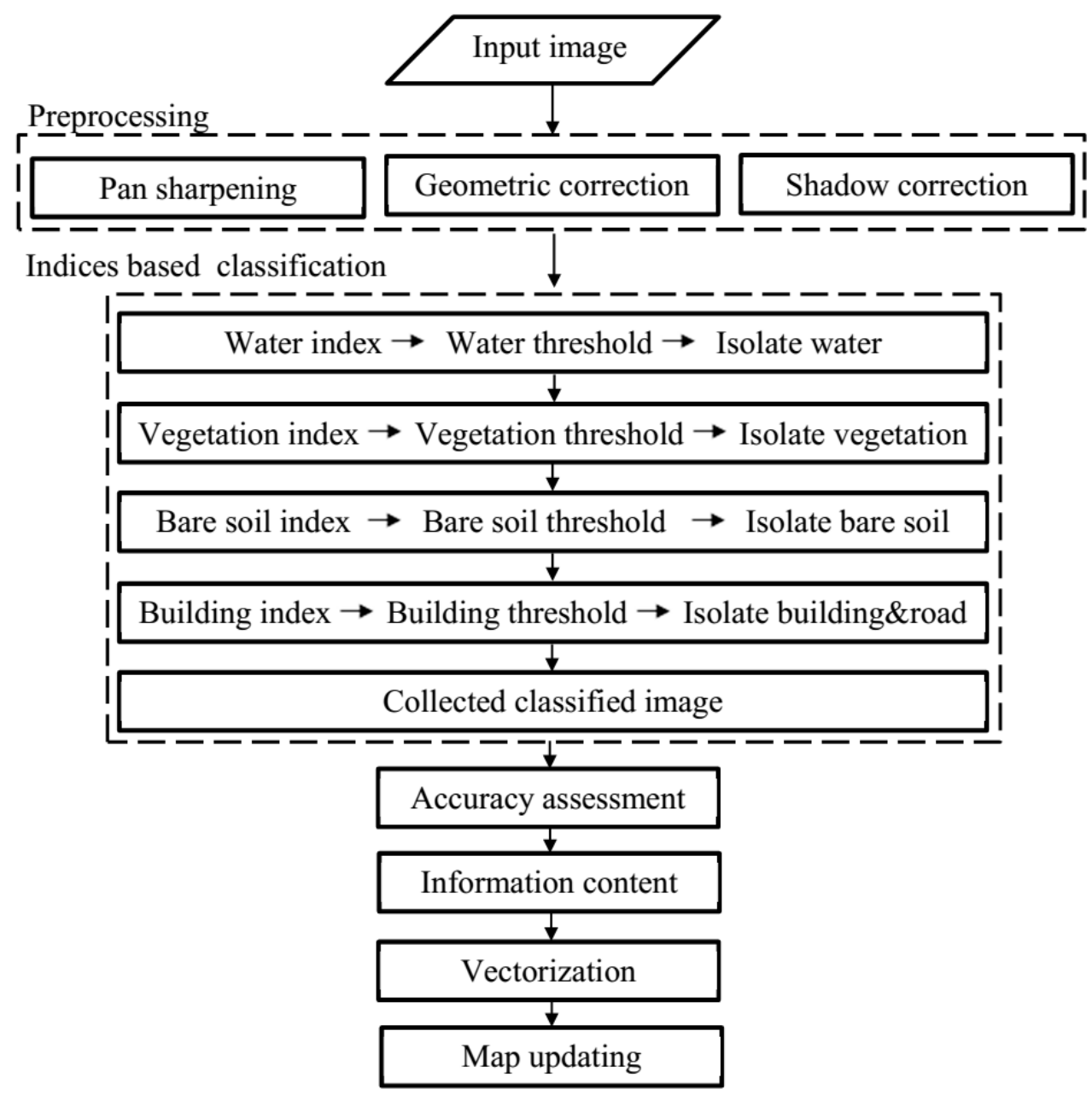

Fig. 1. Methodology flow chart. 


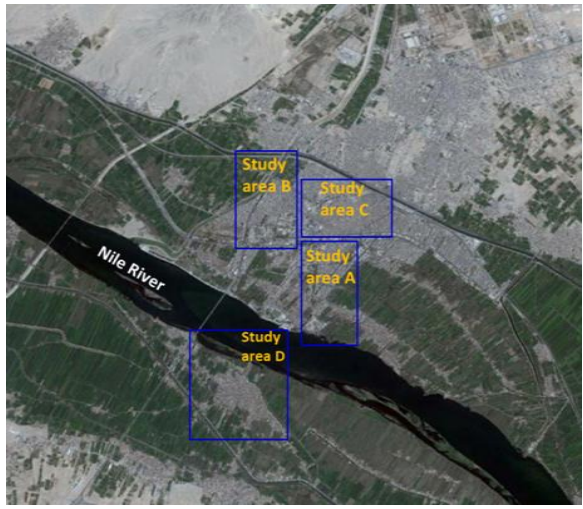

(a)

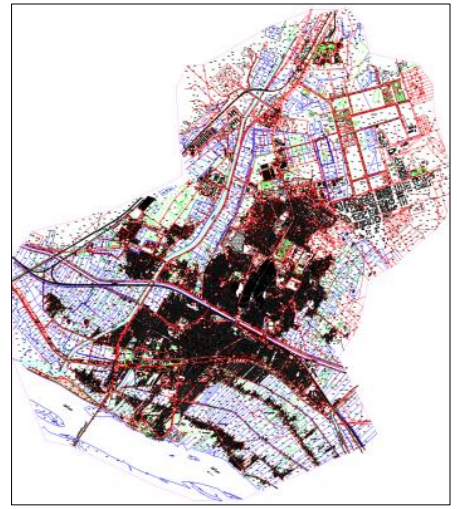

(b)

Fig. 2. Study area, (a) The WorldView-2 image, and (b) 1:5000 Topographic map.

Table 1: WorldView-2 image specification, bands, spectral, and spatial resolutions [10].

\begin{tabular}{|l|c|c|}
\hline Bands & Wavelength $(\mathbf{n m})$ & Resolution (m) \\
\hline Panchromatic Band & $450-800$ & 0.50 \\
\hline Coastal blue & $400-450$ & \\
\hline Blue & $450-510$ \\
\hline Green & $510-580$ \\
\hline Yellow & $585-625$ \\
\hline Red & $630-690$ & \multirow{2}{*}{2.00} \\
\hline Red edge & $705-745$ \\
\hline NIR1 & $770-895$ \\
\hline NIR2 & $860-1040$ & \\
\hline
\end{tabular}

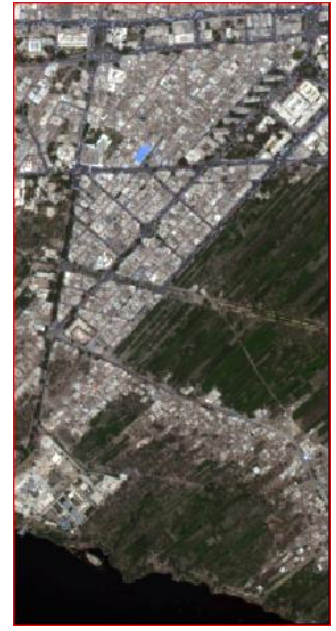

Study area $A$

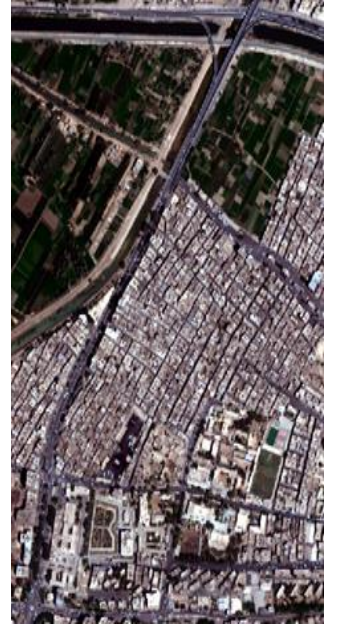

Study area B

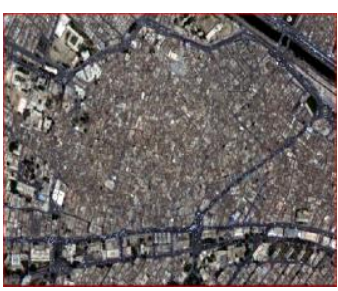

Study area $C$

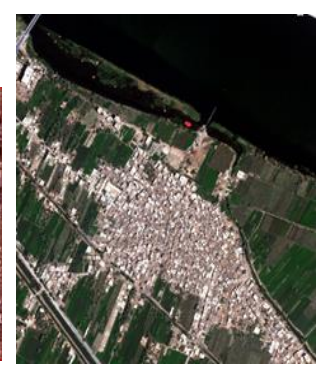

Study area D

Fig. 3. Four used study areas A, B, C, and D. 


\subsection{Data fusion}

A set of data fusion techniques are available and produce good results. Abd Elwahed et al. [11] compared three different techniques for data fusion; Intensity Hue Saturation (IHS), Principal Component Analysis (PCA), and Arithmetic Combination Technique (Brovey Transform). The results of this comparison indicated that all used techniques (IHS, PCA, and Brovey), have shown a good detail increasing, IHS technique has the highest correlation with the original multispectral image, but using PCA technique keeps the number of bands the same before and after merge. In this study, PCA technique was used as it can apply the image fusion for the eight bands of WorldView-2 image, which used in the indices. The Data fusion process was performed in the used images using PCA technique by ERDAS 2015 software. Resampling by the nearest neighbour method was selected to preserve the colour content of the original multispectral image unchanged [12].

\subsection{Geometric correction}

Remote sensing images are inherently subject to geometric distortions. Therefore, they must geometrically register to a known ground coordinate system. According to [11], [12], and [13] an intense work has applied for geometric correction using Translation, Isogonal affine, and Polynomial mathematical models from first to third order polynomial transformation methods. Among the previous techniques, the third-order polynomial transformation method has demonstrated the most promising result for geometric correction. The third-order polynomial transformation method was used in this study to rectify WorldView-2 satellite image to Egyptian Transverse Mercator (ETM) projection using (16) GCPs (Fig. 4). The image was rectified with Root Mean Square (RMS) error in the checkpoints as 0.65 $\mathrm{m}$. The resampling process was carried out by using the nearest neighbour method to avoid smoothing the original image data.

\subsection{Shadow restoration}

Shadow degrades the quality of the information provided by VHR satellite images [14]. Despite the reflectance obtained in the shadow pixels is weak, there is still a valuable information that makes shadow restoration possible [15]. The process of shadow restoration consists of two main steps: detection and compensation. 


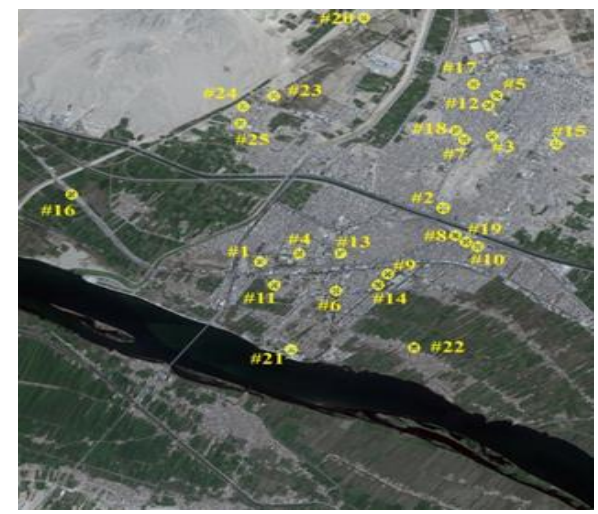

Fig.4 Configuration of Ground Control Points.

\subsubsection{Shadow detection}

The study area selected contains different shadow and water regions. A particular problem can arise such as the misclassification between shadow and water class. Optimized Shadow Index (OSI) proposed by [16] is used to differentiate between shadow and water pixels.

OSI $=\arctan \left(\frac{\min (G, B)}{\mathrm{R}}\right)$

where $\mathrm{R}, \mathrm{G}$, and $\mathrm{B}$ are the red, green, and blue components of each pixel in the image, and min is the minimum function. The shadow areas lie in the valley between the two peaks surrounding the shadow range in OSI image histogram. The X-threshold method is used to separate non-shadow, shadow, and water areas automatically.

\subsubsection{Shadow compensation}

Shadow restoration methods aim to compensate the brightness difference between shadow and non-shadow areas. [17] introduced the Linear Correlation Method (LCC) for shadow compensation as follows:

$\mathrm{DN}=\frac{\sigma_{\text {non-shadow }}}{\sigma_{\text {shadow }}}\left(D N_{\text {shadow }}-\mu_{\text {shadow }}\right)+\mu_{\text {non-shadow }}$

where $D N$ is the digital number of the corrected image. $\sigma_{\text {shadow }}$ and $\sigma_{\text {non-shadow }}$ are the standard deviation of the shadow and non-shadow image, respectively. $\mu_{\text {shadow }}$ and $\mu_{\text {non-shadow }}$ are the mean of shadow and non-shadow image, respectively. $D N_{\text {shadow }}$ is the digital number of the shadow image. Fig. 5 shows shadow compensation results for a part of study area $\mathrm{C}$ contain urban features, water, and shadows. 


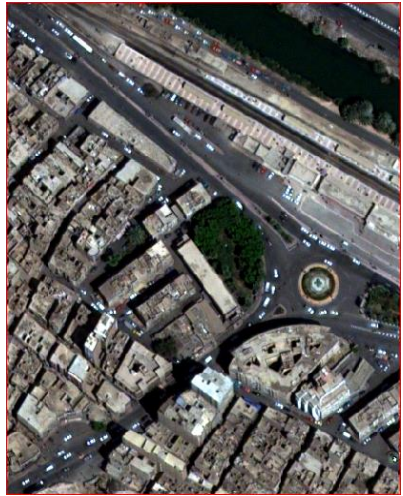

(a)

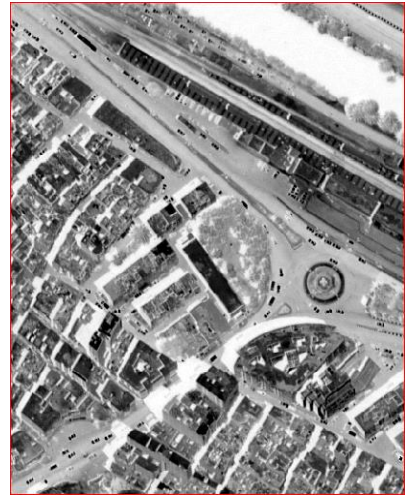

(b)

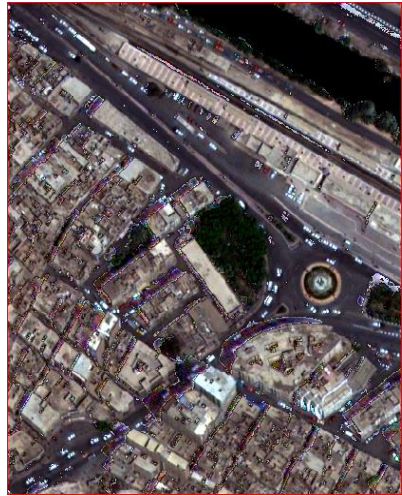

c)

Fig.5 Shadow restoration results; (a) RGB image, (B) OSI image, (c) Shadow corrected image

\section{Feature extraction indices}

Feature extraction using a single band image gives inaccurate results. It will be more convenient to use all the characteristics of the available bands of a multispectral image in the feature extraction process. Fig. 6 shows a different spectral response received by WorldView-2 sensor (coastal, blue, green, yellow, red, red edge, near-infrared1, and near-infrared2) for various land cover classes. The Egyptian environment contains five main classes: water, vegetation, bare soil, building, and road.

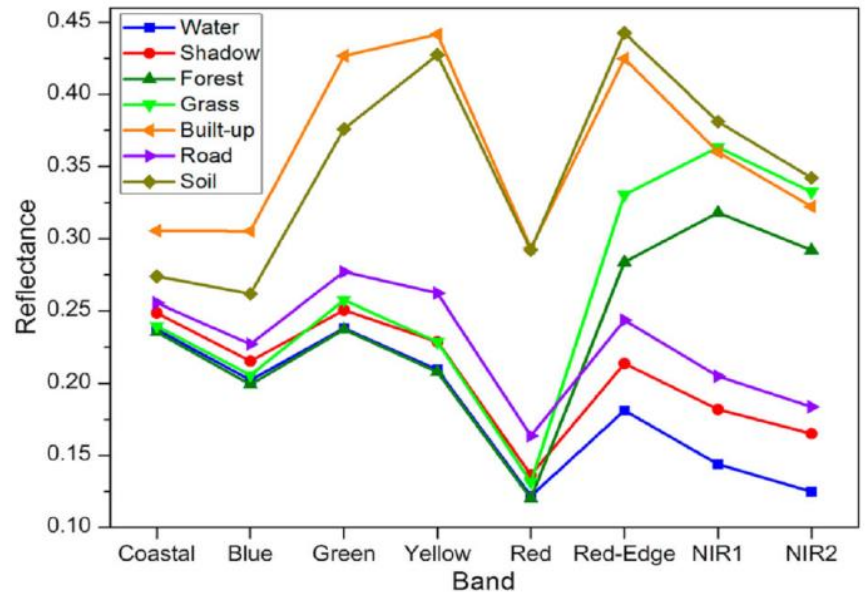

Fig. 6. Spectral responses of land cover classes in WorldView-2 images [18].

Indices can be evaluated based on the concept of error matrices; producer's accuracy, user's accuracy, and the overall accuracy [19]. 
Producer's Accuracies: $\quad \eta=\mathrm{TP} /(\mathrm{TP}+\mathrm{FN})$.

User's Accuracies: $\quad \mathrm{p}=\mathrm{TP} /(\mathrm{TP}+\mathrm{FP})$.

Overall Accuracy: $\quad \tau=(\mathrm{TP}+\mathrm{TN}) /(\mathrm{TP}+\mathrm{TN}+\mathrm{FP}+\mathrm{FN})$.

True positive (TP), False Positive (FP), True Negative (TN), and False Negative (FN) are computed by comparing the ground truth with the segmented foreground/background pixels. TP indicates that the segmented foreground pixels are correct, whereas FP means that the segmented foreground pixels are not real ones. TN indicates that the segmented background pixels are equivalent to the ground truth, whereas FN means that the segmented background pixels are not correct.

\subsection{Water}

Water can be distinguished using the visible blue, green, near-infrared1, and near infrared2 bands from WorldView-2 images depending on the used index. In this research three indices to extract water areas using $\mathrm{X}$-threshold method were compared.

\subsubsection{Normalized Difference Water Index (NDWI)}

NDWI (Eq.6) has developed by normalizing the blue band against the NIR1 band, as the difference in response is very clear. NDWI creates a single grey scale image, where water appears bright [20].

NDWI $=($ Blue band - NIR1 band $) /($ Blue band + NIR1 band $)$

\subsubsection{Modified Normalized Difference Water Index (MNDWI)}

The MNDWI (Eq.7) could enhance open water features while effectively reducing and even removing vegetation, built-up land, and soil noise. The index benefits from the high reflectance of NIR1 by vegetation and bare soil features. As a result, water features have positive values and thus are improved, whereas vegetation and bare soil generally have zero or negative values and therefore are removed [21].

MNDWI $=($ Green band - NIR1 band $) /($ Green band + NIR1 band $)$

\subsubsection{WorldView Water Index (WV-WI)}

WV-WI uses WorldView-2 bands to identify water areas by using coastal and NIR2 bands [22]. The WV-VI is defined as:

WV-WI $=($ Coastal band - NIR2 band $) /($ Coastal band + NIR2 band $)$ 
Water indices were applied to study area A with X-threshold method to select the best index for water extraction. Results showed that these methods have high overall accuracies 91\%, 93\%, and 94\% for NDWI, WV-WI, and MNDWI, respectively. The best results obtained with MNDWI is shown in Fig. 7.

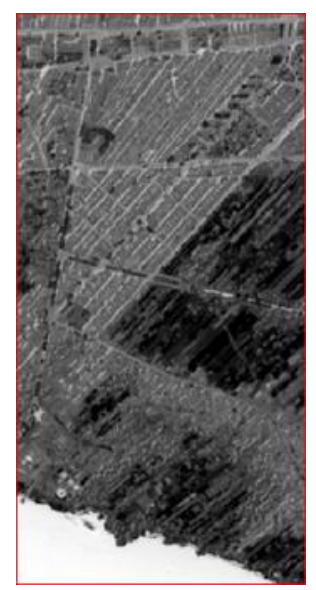

a)

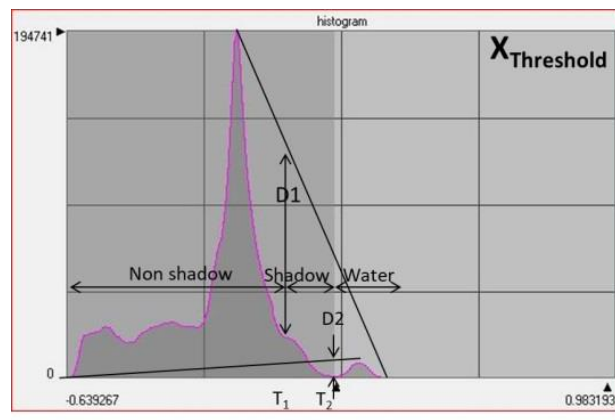

b)

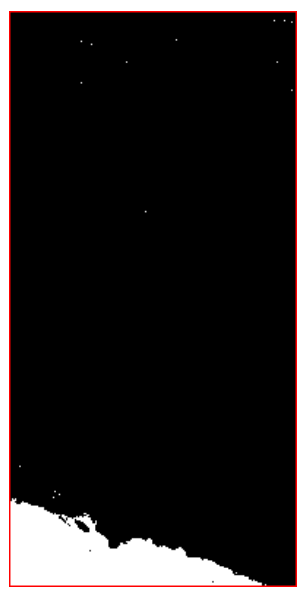

c)

Fig. 7. Water extraction by MNDWI in study area A, a) Index image, b) Xthreshold method in MNDWI histogram, and c) Extracted water areas in white.

\subsection{Vegetation}

The ability of new WorldView-2 image bands for distinguishing vegetated areas from non-vegetated areas was tested [23]. [22] use the ability of additional WorldView-2 satellite bands to improve the tree species identification. Vegetation can be distinguished using the visible red, green, near-infrared1, and near infrared 2 bands. Three indices to extract vegetation areas using Otsu threshold method were compared.

\subsubsection{Normalized Difference Vegetation Index (NDVI):}

In NDVI (Eq.9) green plant leaves usually have low reflectance in the visible regions of the electromagnetic spectrum because of strong absorption by leaf mesophyll. Meanwhile, in the near-infrared region, leaves exhibit high reflectance due to extensive scattering effects in these wavelengths [24].

NDVI $=($ NIR1 band - Red band $) /($ NIR1 band + Red band $)$ 


\subsubsection{WorldView Vegetation Index (WV-VI)}

In WV-VI (Eq.10) the red band offers lower reflectance levels of vegetation than the NIR2 band, which has a higher value than traditional broad NIR bands.

WV-VI $=($ Red band - NIR2 band $) /($ Red band + NIR2 band $)$

\subsubsection{WorldView NDVI (WV-NDVI)}

The spectral capability of the Red Edge band is more sensitive to vegetation chlorophyll content than the red band. The normalized difference vegetation index based on Red Edge and NIR2 bands of WorldView-2 produced high accuracy in the estimation of vegetation compared to the use of Red and NIR1 bands [25].

WV-NDVI $=($ NIR2 band - Red Edge band $) /($ NIR2 band + Red Edge band $)$

Vegetation indices were applied to study area A with Otsu threshold to select the best index for vegetation extraction. Results showed that these methods have good overall accuracies $89 \%, 92.5 \%$, and $92.8 \%$ for WV-NDVI, NDVI, and WV-VI, respectively. The best results obtained with WV-VI is shown in Fig. 8.

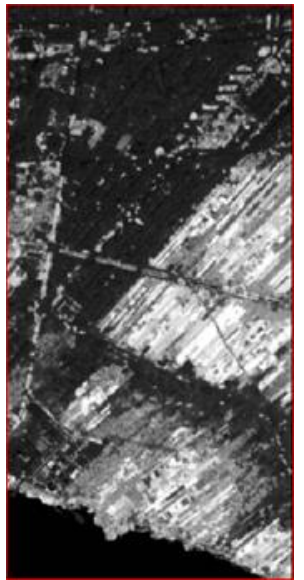

a)

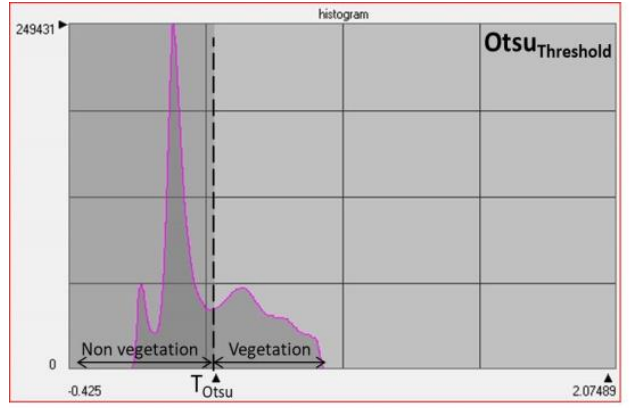

b)

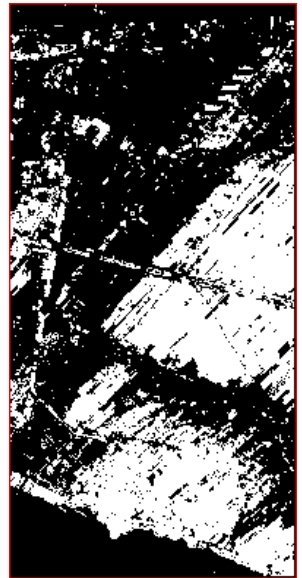

c)

Fig. 8. Vegetation extraction by WV-VI in study area A, a) Index image, b) Otsu threshold, and c) Extracted vegetation areas in white.

\subsection{Bare soil}

One of the most basic classification tasks is to distinguish bare soil from urban areas. Bare soil plays an important role in the ecosystem. A set of 
indices developed for mapping of the bare-soil areas from the satellite images. Three indices to extract bare soil areas using Otsu threshold method were compared.

\subsubsection{Soil Adjusted Vegetation Index (SAVI)}

The SAVI (Eq.12) was developed to decrease soil influences on canopy spectra by integrating a soil adjustment factor $L$ into the denominator of the normalized difference vegetation index equation to reduce the effect of soil background. [26] found that the optimal adjustment factor to vary with vegetation density by using $\mathrm{L}=0.5$. This reduced soil noise considerably throughout a wide range of vegetation amounts.

$\mathrm{SAVI}=\left(\frac{\mathrm{NIR} 1 \text { band }- \text { Red band }}{\mathrm{NIR} 1 \text { band }+ \text { Red band }+\mathrm{L}}\right)(1+\mathrm{L})$

\subsubsection{Modified Soil Adjusted Vegetation Index2 (MSAVI2)}

The modified soil-Adjusted Vegetation Index (MSAVI) and its later revision, $\left(\mathrm{MSAVI}_{2}\right.$ ) (Eq.13), help to solve some of NDVI's restrictions when applied to areas with a high degree of exposed soil surface [27].

$\operatorname{MSAVI}_{2}=\left(2 \mathrm{NIR} 1+1-\sqrt{(2 \mathrm{NIR} 1+1)^{2}-8(\mathrm{NIR} 1-\mathrm{Red})}\right) / 2$

\subsubsection{World view soil index (WV-SI)}

Shortwave Infrared (SWIR) and NIR1 bands are used to represent the difference in reflectance values in soil areas. Representing soil in WorldView-2 image is a challenging process since there is no SWIR band, but there are unique differences in the response values of soil between the green and yellow bands. This artifact can be exploited to represent soil in WV-SI [22] as follows:

WV-SI $=($ Yellow band - Green band $) /($ Yellow band + Green band $)$

Bare soil indices were applied to study area A with Otsu threshold to select the best index for bare soil extraction. Results showed that these methods give $59.25 \%, 85.25 \%$, and $85.75 \%$ overall accuracies for WV-SI, $\mathrm{MSAVI}_{2}$, and SAVI, respectively. The best results obtained with SAVI is shown in fig. 9. 


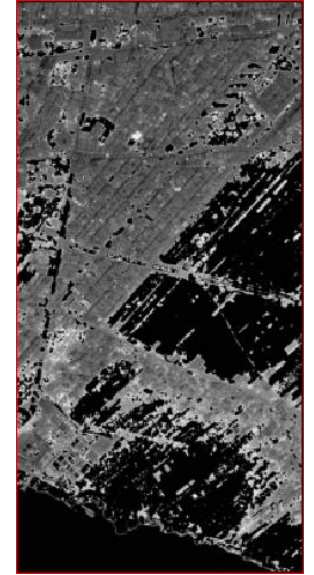

a)

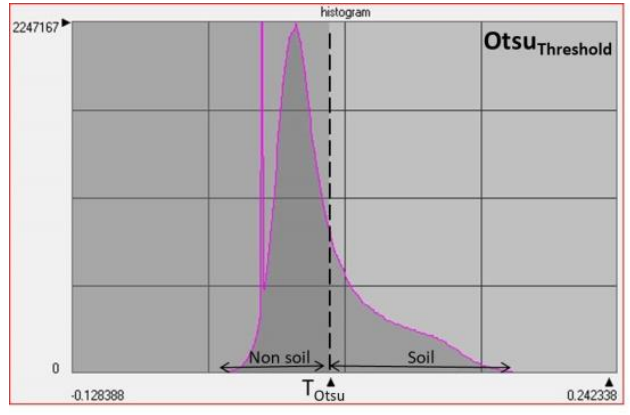

b)

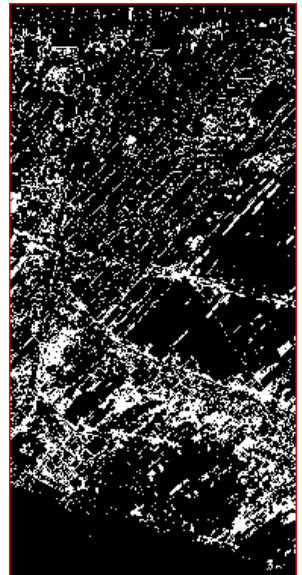

c)

Fig. 9. Bare soil extraction by SAVI in study area A, a) Index image, b) Otsu threshold, and c) Extracted bare soil areas in white.

\subsection{Building}

A set of building indices has been developed using the new WorldView-2 bands such as WorldView Building Index (WV-BI) and Building spectral index (BSI). The two indices using Otsu threshold method were compared for building extraction.

\subsubsection{WorldView Building Index (WV-BI)}

WV-BI (Eq.15) is used in classifying areas that contrast against the background, which can be classified as manmade. Non-homogeneous features appear to be brighter in response than the background. To exploit these features, the difference between the red edge and coastal bands will provide an effective means of segregating these features [22].

$\mathrm{WV}-\mathrm{BI}=($ Coastal band - Red Edge band $) /($ Coastal band + Red Edge band $)$

\subsubsection{Building spectral index (BSI)}

BSI (Eq.16) was developed using two significant bands: band4 (yellow) and band7 (NIR1). Bands were selected using multi-objective Particle Swarm Optimization (PSO). PSO was used to choose the suitable bands from the different spectral bands of WorldView-2 image to form the index. Multiobjective optimization has been used to minimize the number of chosen spectral bands to optimize classification accuracy [28].

$\mathrm{BSI}=($ Yellow band $-2 \mathrm{NIR} 1$ band $) /($ Yellow band + 2NIR1 band $)$ 
Building indices were applied to study area A with Otsu threshold to select the best index for building extraction. Results showed that these methods have good overall accuracies, $86.5 \%$ and $91 \%$ for BSI and WV-BI, respectively. The best results obtained with WV-BI is shown in Fig. 10.

\section{Proposed indices-based method}

The previous indices were applied and tested on the four study areas (Fig. 3) and evaluated to select the most suitable indices for the land cover classes in the Egyptian environment. Indices selected are MNDWI for water, WV-VI for vegetation, SAVI for bare soil, and WV-BI for building. The remaining feature is considered as road. An automatic model was designed in ERDAS 2015 model maker to apply the suggested indices in consecutive order. The approach has been applied to the four study areas, and results are shown in fig. 9. Accuracy assessment (producer accuracy, user accuracy, overall accuracy, and kappa coefficient) is applied to evaluate the accuracy of the proposed approach. The number of samples of the reference data is determined to be at least 50 samples per class included in the error matrix. Samples number for each category might be adjusted based on the relative importance of that category for a particular application [12]. The study area contains five classes, so $50 \times 5=250$ samples can be considered. To satisfy the importance and variability within each category 150 samples were added over 250 samples to be 400 samples. Table 2 shows the accuracies of the classified images.

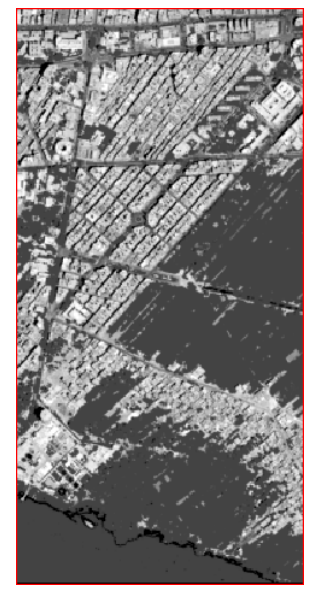

a)

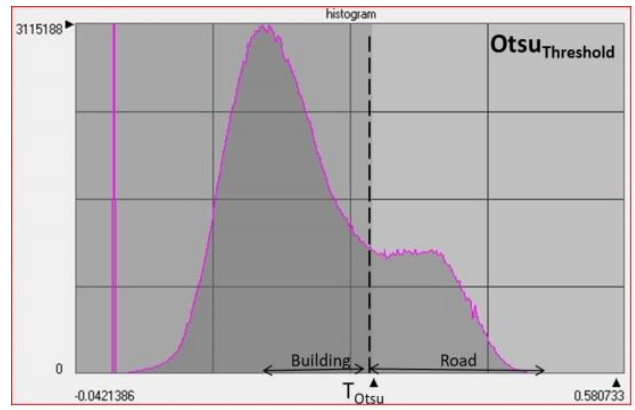

b)

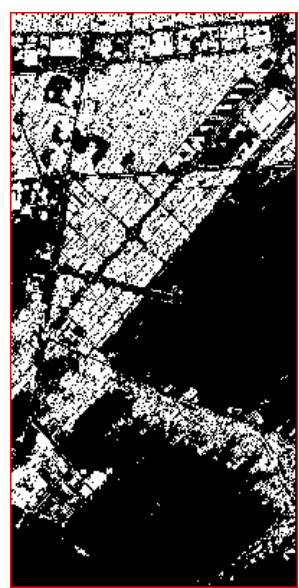

c)

Fig. 10. Building extraction by WV-BI in study area A, a) Index image, b) Otsu threshold, and c) Extracted building areas in white. 


\section{Standard image classification methods}

The obtained results have to be compared with traditional pixel-based classification methods, which available in Erdas2015 software, to validate the stability and efficiency of the proposed approach. Training areas of different land cover types (water, vegetation, bare soil, building, and road) were selected. Then, supervised classification was carried out with five traditional classification methods; minimum distance, spectral angle mapper, mahalanobis distance, spectral correlation mapper, and maximum likelihood method, which included in ERDAS 2015 software. The classification methods were applied to the four study areas, and the results (Fig. 11) were evaluated as shown in Table 3.

Table 2: Indices based method results for the four study areas.

\begin{tabular}{|c|c|c|c|c|c|}
\hline \multicolumn{2}{|c|}{} & Study area A & Study area B & Study area C & Study area D \\
\hline \multirow{4}{*}{$\begin{array}{c}\text { Producer } \\
\text { Accuracy } \\
\%\end{array}$} & Water & 97.10 & 52.83 & 93.22 & 82.22 \\
\cline { 2 - 6 } & Vegetation & 75.81 & 84.38 & 77.19 & 93.60 \\
\cline { 2 - 6 } & Bare soil & 56.00 & 36.07 & 5.66 & 44.59 \\
\cline { 2 - 6 } & Road & 100.00 & 65.67 & 84.00 & 57.41 \\
\cline { 2 - 6 } & Building & 77.57 & 88.62 & 84.53 & 82.46 \\
\hline \multirow{4}{*}{$\begin{array}{c}\text { Uccuracy } \\
\%\end{array}$} & Water & 100.00 & 100.00 & 87.30 & 98.67 \\
\cline { 2 - 6 } & Vegetation & 95.92 & 98.78 & 100.00 & 96.69 \\
\cline { 2 - 6 } & Bare soil & 53.85 & 50.00 & 100.00 & 76.74 \\
\cline { 2 - 6 } & Road & 57.47 & 56.41 & 45.65 & 53.45 \\
\cline { 2 - 6 } & Building & 86.46 & 64.88 & 77.27 & 45.63 \\
\hline \multicolumn{2}{|c|}{ Overall Accuracy \% } & 80.50 & 71.00 & 74.25 & 75.50 \\
\hline \multicolumn{2}{|c|}{ Overall KAPPA } & 0.75 & 0.62 & 0.64 & 0.69 \\
\hline
\end{tabular}

Table 3: Standard image classification method results for four study areas.

\begin{tabular}{|c|c|c|c|c|c|}
\hline $\begin{array}{c}\text { Classification } \\
\text { method }\end{array}$ & Accuracy & $\begin{array}{r}\text { Study } \\
\text { area A }\end{array}$ & $\begin{array}{l}\text { Study } \\
\text { area B }\end{array}$ & $\begin{array}{l}\text { Study } \\
\text { area } C\end{array}$ & $\begin{array}{l}\text { Study } \\
\text { area D }\end{array}$ \\
\hline \multirow{2}{*}{$\begin{array}{l}\text { Maximum } \\
\text { likelihood }\end{array}$} & Overall Accuracy \% & 79.00 & 74.00 & 77.00 & 83.00 \\
\hline & KAPPA & 0.73 & 0.66 & 0.66 & 0.78 \\
\hline \multirow{2}{*}{$\begin{array}{c}\text { Minimum } \\
\text { distance }\end{array}$} & Overall Accuracy \% & 55.25 & 46.50 & 52.50 & 61.75 \\
\hline & KAPPA & 0.46 & 0.33 & 0.40 & 0.53 \\
\hline \multirow{2}{*}{$\begin{array}{c}\text { Mahalanobis } \\
\text { distance }\end{array}$} & Overall Accuracy \% & 79.00 & 64.50 & 75.50 & 75.50 \\
\hline & KAPPA & 0.72 & 0.55 & 0.62 & 0.69 \\
\hline \multirow{2}{*}{$\begin{array}{c}\text { Spectral angle } \\
\text { mapper }\end{array}$} & Overall Accuracy \% & 68.50 & 68.75 & 67.00 & 73.75 \\
\hline & KAPPA & 0.61 & 0.61 & 0.57 & 0.67 \\
\hline \multirow{2}{*}{$\begin{array}{c}\text { Spectral } \\
\text { correlation mapper }\end{array}$} & Overall Accuracy $\%$ & 76.75 & 71.75 & 73.00 & 84.50 \\
\hline & KAPPA & 0.70 & 0.64 & 0.65 & 0.80 \\
\hline
\end{tabular}




\section{Information content}

Any geoinformation acquisition system can be evaluated by the useful information content in the data collected by such a system [29]. In this respect, the information content of WorldView-2 images was analysed by mapping urban features of Qena governorate (Fig.12) and comparing the results with the reference map at scale 1:5000. The Egyptian environment can be grouped into four main categories; cultural, transportation, vegetation, and hydrological feature [30].



Fig. 11. Results of indices based and pixel-based methods on the 4 study areas. 
Table 4 demonstrates that WorldView-2 images could be rated based on the National Imagery Interpretability Rating Scale (NIIRS) as 5. The results show that WorldView-2 images can be utilized for generating and updating 1:5000 maps of urban areas.

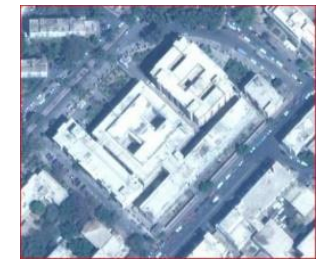

Government building

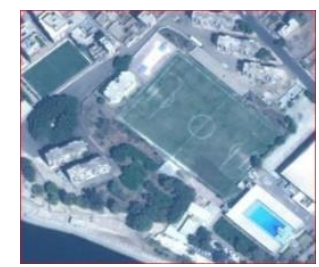

Playground

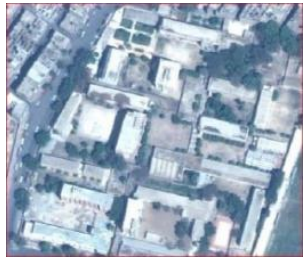

School

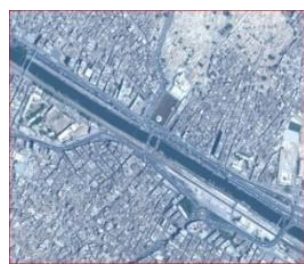

Canal

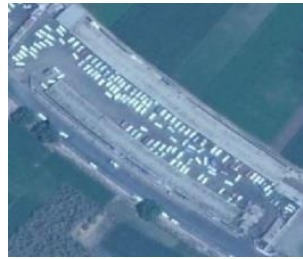

Road \& Barking

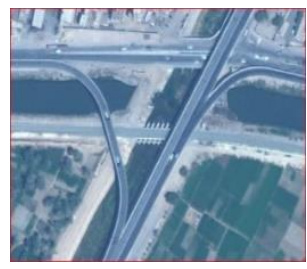

Bridge \& Canal

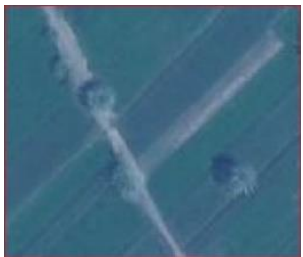

single tree \& palm

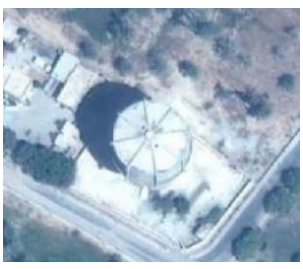

Water tank

Fig. 12. Urban features on WorldView-2 image

Table 4: Evaluation of WorldView-2 information content with 1:5000 map information content.

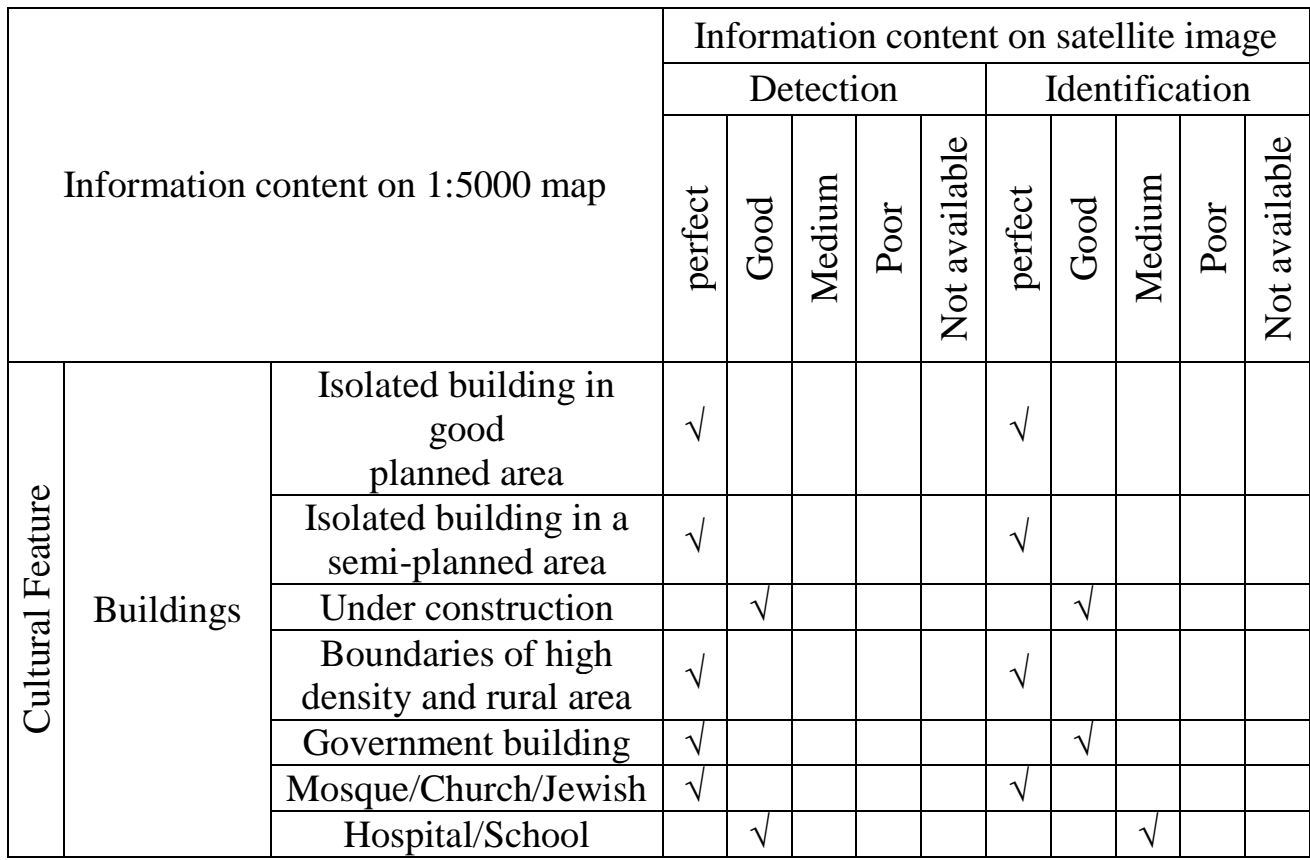


JES, Assiut University, Faculty of Engineering, Vol. 48, No. 5, September 2020, pp. 845-868

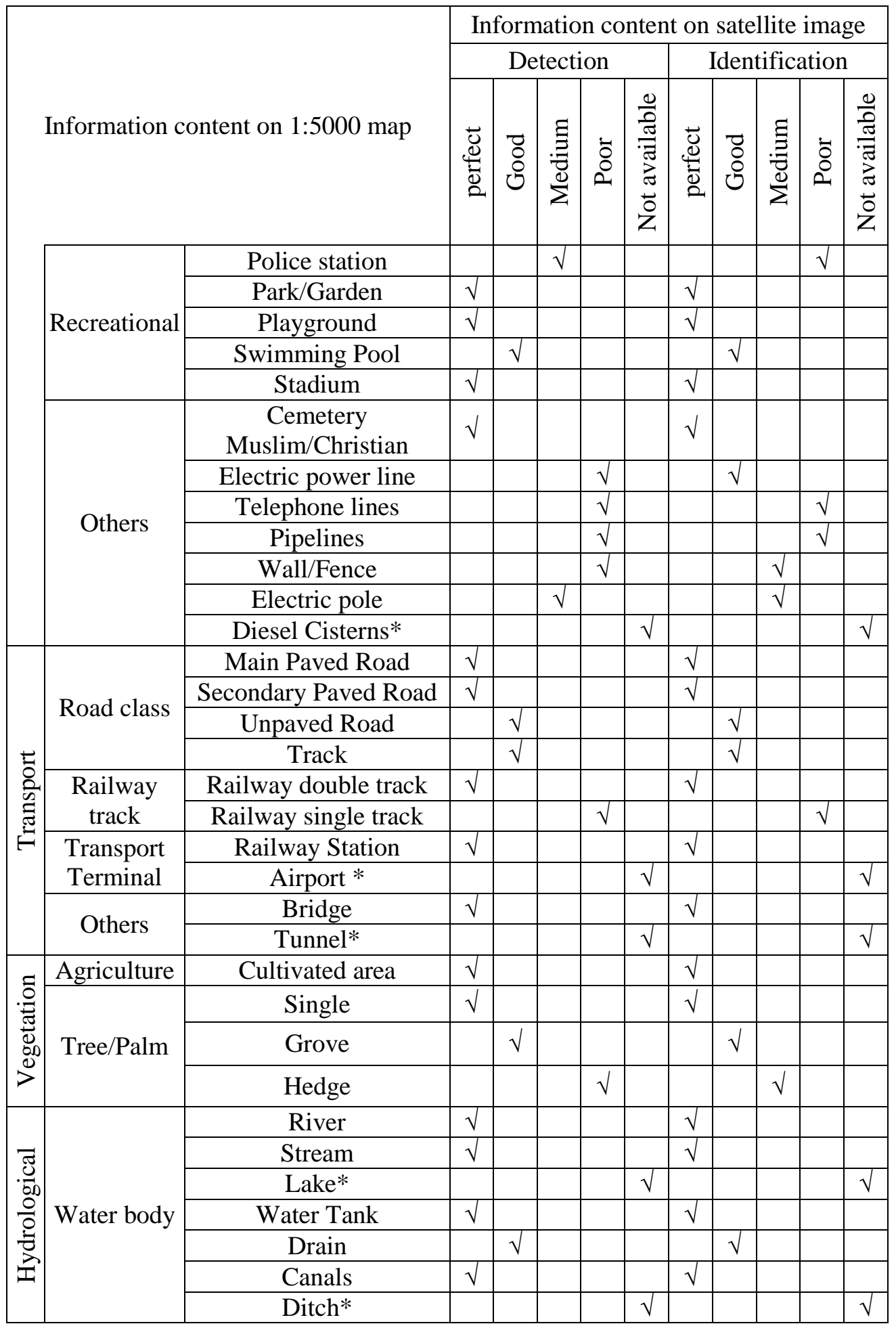

*Features not available in the study area 


\section{Map updating}

The extracted data in study area B, which has the most changes in the study areas compared with the old map, are chosen for map updating. The vectorization process is applied to convert raster image resulted from classification with the proposed method to vector format. This process was made through ERDAS 2015 software. The extracted data are compared with the old map to detect the changes. The most common quality measurements for extracted building are Building Extraction Rate (BER) (eq.17) and Roof Area Coverage (RAC) (eq.18) [12], BER and RAC are counting considering the $25 \%$ coverage threshold.

Building Extraction Rate $(B E R)=\frac{B C E}{B C E+B N E}=373 /(373+51)=87.97 \%$

where BCE is the "Building Correctly Extracted" and BNE is the number of "Buildings Not Extracted".

Roof Area Coverage $(\mathrm{RAC})=\frac{\mathrm{EBA}}{\mathrm{RPA}}=320028 / 357618=89.49 \%$

where EBA is the total "Extracted Building Areas" and RPA is total "Reference Polygon Areas".

The quantitative assessment of the final extracted roads is carried out against the reference data set using two basic quality measures: completeness, and correctness. The completeness is the ratio of the reference road data matched with the extracted road data to the total length of the reference road network (Eq.19). It indicates the ability of the road network extraction methods to extract the road network from an image.

Completeness $=\frac{\text { Length of } \text { matched reference }}{\text { Length of reference }}=6513 / 7780=83.71 \%$

The correctness is the ratio of the extracted road data matched with the reference road data to the total length of the extracted road network (Eq.20).

Correctness $=\frac{\text { Length of } \text { matched extraction }}{\text { Length of extraction }}=6513 / 7110=91.60 \%$

Fig.13 shows the areas that have been updated in study area B. The correct buildings area extracted from WorldView-2 image was 6.00\% ((357618$337398 / 337398) \times 100)$ more than that in the reference map. Also, roads 
length has increased in the Worldview-2 image. It was $11.41 \%((8668-$ $7780 / 7780) \times 100$ ) more than that in the reference map.

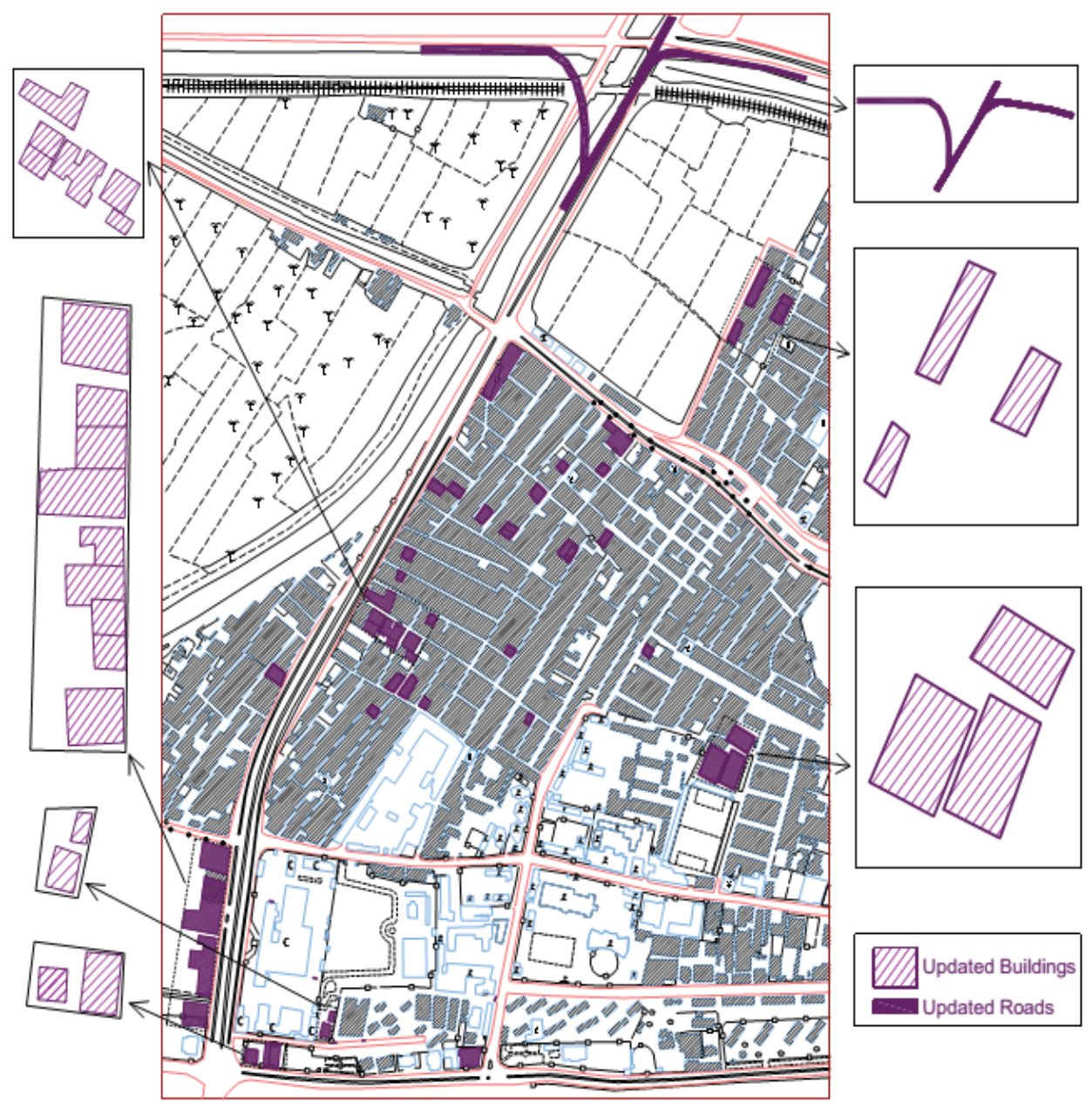

Fig. 13. The reference 1:5000 map showing the updated region in study area B.

\section{Results and discussion}

Different indices to extract urban features were compared. Indices: MNDWI for water, WV-VI for vegetation, SAVI for bare soil, and WV-BI for building give the highest results and are selected to form the proposed method. The results obtained using the proposed method (average overall accuracy $75.31 \%$ ) are higher than those obtained using Minimum distance (54.0\%), Spectral angle mapper (69.50\%), and Mahalanobis distance (73.63\%). Also, results are near to those obtained by the Spectral correlation mapper method (76.50\%) and the Maximum likelihood method (78.25\%). 
The proposed method gives satisfactory results for feature extraction in the Egyptian environment. It gives a good result in classifying water, vegetation, and building, on the other hand, the results are non-uniform for bare soil and road, due to the similarity on spectral response between bare soil, road, and buildings.

The updated map of study area B added a large quantity of information to the original map. It is worth mentioning that the satellite image is acquired in 2017 and the reference map had field revision in 2006. The comparison between areas of the buildings shows a significant difference in the buildings area. The correct building's area extracted from WorldView-2 image is $6.00 \%$ more than that in the reference map. Most of the changes from vegetation to urban are caused by new settlements and the growth in the urban area over the adjacent vegetation area. Also, there are new roads have increased in the WorldView-2 image. It was $11.41 \%$ more than that in the reference map. The increase in roads is due to establishing a new bridge in the upper part of the reference map.

The main advantages of the proposed approach over the other methods that it doesn't need selecting training areas for classification, saving time and effort in comparison with the manual methods, and a flexible method that can be developed by using new indices with their thresholds suitable for any environment. And Its suitability for updating medium scale maps. While the proposed method needs more future work in the Egyptian environment to enhance its results by using more suitable indices and more accurate thresholds.

\section{Conclusions}

In this paper, an indices-based classification method for feature extraction from VHR satellite images is proposed. The method was evaluated and compared with traditional pixel-based classification methods. Results of this comparison demonstrate that average overall accuracy achieved using the proposed approach is higher than those obtained using Minimum distance, Spectral angle mapper, and Mahalanobis distance. Also, it is close to those obtained by the Spectral correlation mapper and Maximum likelihood method. The main advantage of the proposed method over the other methods that it does not need selecting training areas for classification. In addition to its stability in urban feature extraction from VHR images for updating medium scale maps in the Egyptian environment. However, it still worth further study to improve the proposed method by using additional indices to extract subtle urban features. 


\section{References}

[1] Samsudin, S.H., H.Z. Shafri, and A. Hamedianfar, Development of spectral indices for roofing material condition status detection using field spectroscopy and WorldView-3 data. Journal of Applied Remote Sensing, 2016. 10(2): p. 025021.

[2] Salehi, B., Y. Zhang, and M. Zhong, Combination of object-based and pixelbased image analysis for classification of vhr imagery over urban areas. in Proceedings of ASPRS 2011 Annual Conference. 2011.

[3] Digital-Globe, "page title: satellite imagery - image library https://api.discover.digitalglobe.com/show?id=103001006889A200-february 2020".

[4] Nouri, H., S. Beecham, S. Anderson, and P. Nagler, High spatial resolution WorldView-2 imagery for mapping NDVI and its relationship to temporal urban landscape evapotranspiration factors. Remote sensing, 2014. 6(1): p. 580-602.

[5] Otsu, N., A threshold selection method from gray-level histograms. IEEE transactions on systems, man, and cybernetics, 1979. 9(1): p. 62-66.

[6] Nagao, M., T. Matsuyama, and Y. Ikeda, Region extraction and shape analysis in aerial photographs. Computer Graphics and Image Processing, 1979. 10(3): p. 195-223.

[7] Chen, Y., D. Wen, L. Jing, and P. Shi, Shadow information recovery in urban areas from very high resolution satellite imagery. International Journal of Remote Sensing, 2007. 28(15): p. 3249-3254.

[8] Yamazaki, F., W. Liu, and M. Takasaki. Characteristics of shadow and removal of its effects for remote sensing imagery. in 2009 IEEE International Geoscience and Remote Sensing Symposium. 2009. IEEE.

[9] Egyptian Military Survey, Egypt Administrative Boundaries, Qena governorate administrative boundaries map, the latest update Mar 2020.

[10] DG Staff, The Benefits of the 8 Spectral Bands of WorldView-2: Applications Whitepaper. London, DigitalGlobe, Technical Report WP-8SPEC Rev.

[11] Abd Elwahed, A., A. Farrag, A. Abdelhafiz, and M. Besheer, Potential of using high resolution satellite images for mapping applications. Journal of Engineering Sciences, Assiut University, 2011. 39(3): p. 513-528.

[12] Mostafa, F. A., Y. G. Mostafa, M. A. Yousef, and Y. A. Abas, Using of high resolution satellite images for updating large scale mapping in Egypt. J. Eng. Sci, 2014. 42: p. 1122-1137.

[13] Nady, B., Y. Mostafa, Y. A. Abbas, and M. Enieb, Using of VHR satellite images for road network extraction in Egypt. Journal of Engineering Sciences, 2020. 48(1): p. 20-31.

[14] Mostafa, Y., M. Yousef, and F. Mostafa, A new shadow detection index for 8band very high-resolution satellite images. International Journal of Remote Sensing, 2020. 41(2): p. 420-432.

[15] Mostafa, Y. and M.A. Abdelwahab, Corresponding regions for shadow restoration in satellite high-resolution images. International Journal of Remote Sensing, 2018. 39(20): p. 7014-7028. 
[16] Mostafa, Y. and A. Abdelhafiz, Shadow identification in high resolution satellite images in the presence of water regions. Photogrammetric Engineering \& Remote Sensing, 2017. 83(2): p. 87-94.

[17] Sarabandi, P., F. Yamazaki, M. Matsuoka, and A. Kiremidjian, Shadow detection and radiometric restoration in satellite high resolution images. in IGARSS 2004. 2004 IEEE International Geoscience and Remote Sensing Symposium. 2004. IEEE.

[18] Xie, C., X. Huang, W. Zeng, and X. Fang, A novel water index for urban highresolution eight-band WorldView-2 imagery. International Journal of Digital Earth, 2016. 9(10): p. 925-941.

[19] Story, M. and R.G. Congalton, Accuracy assessment: a user's perspective. Photogrammetric Engineering and Remote Sensing, 1986. 52(3): p. 397-399.

[20] Gao, B.-C., NDWI-A normalized difference water index for remote sensing of vegetation liquid water from space. Remote sensing of environment, 1996. 58(3): p. 257-266.

[21] Xu, H., Modification of normalised difference water index (NDWI) to enhance open water features in remotely sensed imagery. International Journal of Remote Sensing, 2006. 27(14): p. 3025-3033.

[22] Wolf, A.F, Using WorldView-2 Vis-NIR multispectral imagery to support land mapping and feature extraction using normalized difference index ratios. in Algorithms and Technologies for Multispectral, Hyperspectral, and Ultraspectral Imagery XVIII. 2012. International Society for Optics and Photonics.

[23] Belgiu, M., L. Drăguţ, and J. Strobl, Quantitative evaluation of variations in rule-based classifications of land cover in urban neighbourhoods using WorldView-2 imagery. ISPRS Journal of Photogrammetry and Remote Sensing, 2014. 87: p. 205-215.

[24] Myeong, S., D. J. Nowak, P. F. Hopkins, and R. H. Brock, Urban cover mapping using digital, high-spatial resolution aerial imagery. Urban Ecosystems, 2001. 5(4): p. 243-256.

[25] Kumar, A., A.C. Pandey, and A. Jeyaseelan, Built-up and vegetation extraction and density mapping using WorldView-II. Geocarto international, 2012. 27(7): p. 557-568.

[26] Huete, A.R., A soil-adjusted vegetation index (SAVI). Remote sensing of environment, 1988. 25(3): p. 295-309.

[27] Qi, J., A. Chehbouni, A. Huete, Y. Kerr, and S. Sorooshian, A modified soil adjusted vegetation index. Remote sensing of environment, 1994. 48(2): $p$. 119-126.

[28] Sameen, M.I. and B. Pradhan, A novel built-up spectral index developed by using multiobjective particle-swarm-optimization technique. in IOP Conference Series: Earth and Environmental Science. 2016. IOP Publishing.

[29] Farrag, A., Map Updating Using Digital Techniques with Emphasis on SPOT Images". PhD Thesis, Faculty of Engineering., Assiut University Egypt. 1991.

[30] Abd Elwahed, A., A. Farrag, and Y. Moustafa, Evaluation of Information Content and Feature Extraction Capability from Egypt Sat-1 Images. Journal of Engineering Sciences, Assiut University, 2011. 39(3): p. 529-538. 


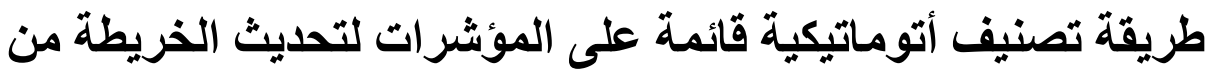 صور الأقمار الصناعية عالية الدقة الدئة}

الملخص العربي

يعد استخر اج المعالم الحضرية لسطح الأرض باستخدام صور الأقمار الصناعية عالية

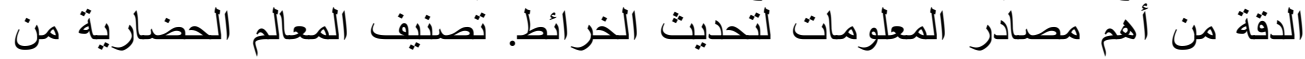

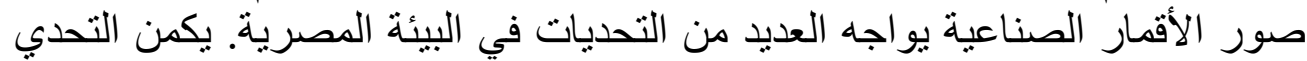

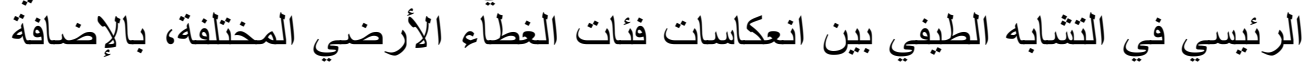

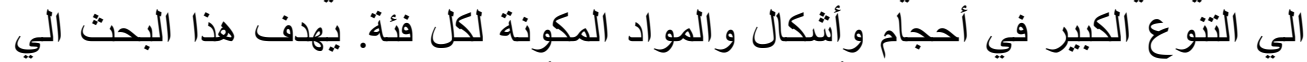

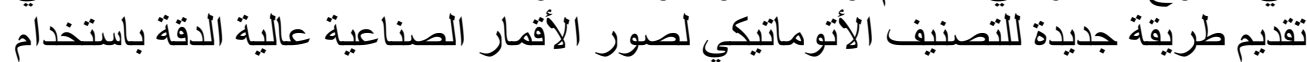

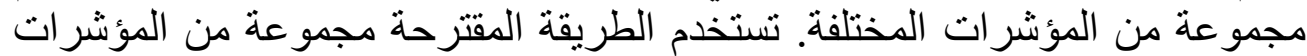

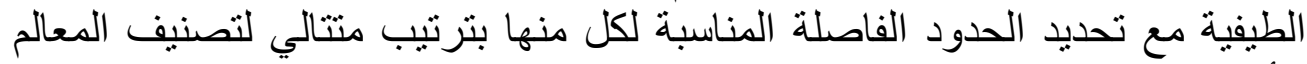
الأرضية في البيئة المصرية. تم استخدام صورة من القمر الصنة الصناعي (WorldView-2) المكونة من ثماني نطاقات

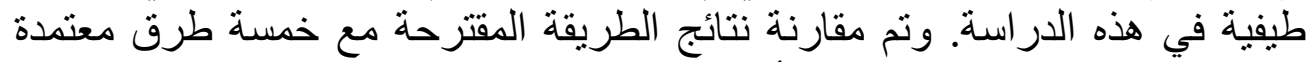

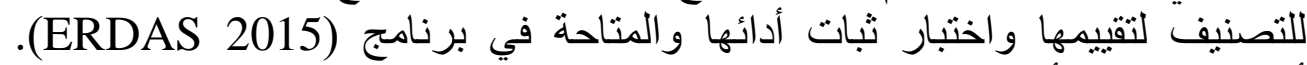
أظهرت النتائج أن الطريقة المقترحة حققت نجاحا في التصنيف فاتجن تخطي نتائج طرق Minimum distance, Spectral angle mapper, and Mahalanobis Spectral كما اقتربت النتائج بشكل ملحوظ من نتائج طرق distance correlation mapper and Maximum likelihood method

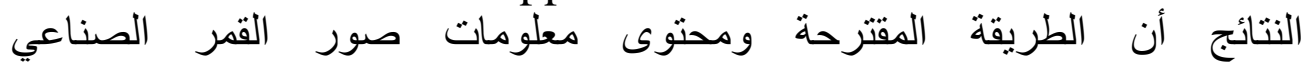
يمكن استخدامها في تحديث الخر ائط في البيئة المصرية. (WorldView-2) 